Kuhn's Structure Four and a Half Decades Later

Author(s): Jed Z. Buchwald

Reviewed work(s):

Source: Historical Studies in the Natural Sciences, Vol. 42, No. 5 (November 2012), pp. 485-490

Published by: University of California Press

Stable URL: http://www.jstor.org/stable/10.1525/hsns.2012.42.5.485

Accessed: 02/01/2013 11:24

Your use of the JSTOR archive indicates your acceptance of the Terms \& Conditions of Use, available at http://www.jstor.org/page/info/about/policies/terms.jsp

JSTOR is a not-for-profit service that helps scholars, researchers, and students discover, use, and build upon a wide range of content in a trusted digital archive. We use information technology and tools to increase productivity and facilitate new forms of scholarship. For more information about JSTOR, please contact support@jstor.org. 


\section{Kuhn's Structure Four and a Half Decades Later}

I first read The Structure of Scientific Revolutions in the fall of '67 at Princeton as a freshman during a yearlong course on the history of science taught by Tom Kuhn, with teaching assistants Mike Mahoney and Ted Brown. We were required to write a long essay at the end of the year. Though it's now nearly half a century, making details rather vague, I recall being taken by Kuhn's novel view of science, novel to me at least. It must have made quite an impression because my essay was titled "The Decline of the Mechanical Ether: A Study in Paradigmatic Progression." At the time just what a paradigm was remained somewhat fuzzy to me, a fact brought home rather strongly by Kuhn's favorable but tough remarks on my essay. We had the opportunity to discuss that and other issues over the next four years as I took other courses with him and became his and Mahoney's research assistant.

Anyone who encounters Structure takes away at least the following claims: that scientists working in a given area together hold to a "paradigm" that guides the way they think about their subject (from theory through the design, execution, and interpretation of experiments), that group members use the paradigm to solve puzzles as they pursue "normal" scientific work, that problems may eventually fracture the paradigm's coherence as "anomalies" begin to show (usually from experiments originally undertaken in "normal" research, but perhaps from internal problems affecting consistence), that these may lead some members of the group, or perhaps aspiring entrants, to question basic elements of the scheme, and that, often in a flash of new insight, a "revolution" occurs that replaces the previous paradigm with a new one. How much of this guided my own work in the past, and how much remains useful today?

My first book concentrated on the structures by means of which a group of British physicists produced a purely continuum-based account of

*Division of Humanities and Social Sciences, MC IOI-40, California Institute of Technology, Pasadena, CA, 9II25; buchwald@its.caltech.edu.

Acknowledgments I thank Michael Gordin for comments on a draft of this article.

Historical Studies in the Natural Sciences, Vol. 42, Number 5, pps. 485-490. ISSN 1939-1811, electronic ISSN 1939-182X. (C) 2012 by the Regents of the University of California. All rights reserved. Please direct all requests for permission to photocopy or reproduce article content through the University of California Press's Rights and Permissions website, http://www.ucpressjournals.com/reprintinfo.asp. DOI: 10.1525/hsns.2012.42.5.485. 
electrodynamics. ${ }^{1}$ The book aimed to uncover the practices of these investigators as they sought solutions to specific problems, both on paper and in the laboratory, and in that sense focused on what Kuhn termed "normal science." But, in addition, I sought to locate the points of divergence between that way of working and related areas of investigation in Germany, France, and Italy-to locate, loosely, something like the "incommensurabilities" that Kuhn had in mind in specific situations. The book concluded with an account of the experimental work on magneto-optics in Germany and Holland that, I argued, produced an "anomalistic" situation that led there to the first concerted introduction of microphysical reasoning and, in England, to abrogating the underpinnings of a continuum-based electrodynamics.

None of this dealt explicitly with Kuhn's Structure, but the approach taken was powerfully influenced by his way of treating past science. Much of that was learned directly from him, however, and not pari passu from Structure itself. Which is perhaps not surprising, since on Kuhn's account it is only through exemplary situations, often learned directly in the apprentice-like training that students undergo, that one learns how to work a particular system. Neither did From Maxwell claim anything like a "revolution" of the sort that, for example, might be thought to characterize the development of optics at the beginning of the nineteenth century, which was the subject of my second book. ${ }^{2}$

Perhaps the most important lesson that those of us who studied under Kuhn learned from him, and that does appear, if only implicitly, in Structure, is that the deepest, most characteristic elements that constitute a field of scientific practice are precisely the ones that are the least obvious and must be learned through the comparative assimilation of instantiating situations, or what Kuhn came to term "exemplars." In Wave Theory I sought explicitly to uncover those unspoken ways of working, and in so doing argued that what appeared on the surface to be the primary points at issue in the debates that eventuated in the theory's spread were not in fact the principal ones at all.

In Structure Kuhn had cited the transition to wave optics as an example of crisis producing a revolution, that here we had "Thomas Young's first accounts of the wave theory of light [appearing] at a very early stage of a developing crisis in optics" (86). But was there a "crisis" at the time, and, if so did it occur before

I. Jed Z. Buchwald, From Maxwell to Microphysics: Aspects of Electromagnetic Theory in the Last Quarter of the Nineteenth Century (Chicago: University of Chicago Press, 1985).

2. Jed Z. Buchwald, The Rise of the Wave Theory of Light: Aspects of Optical Theory and Experiment in the First Third of the Nineteenth Century (Chicago: University of Chicago Press, 1989). 
the substantial evolution of a new system? In Wave Theory I argued, first, that there was no crisis at the time when Young evolved his novel scheme and that the issue of diffraction, which in retrospect seemed so important, had long been set to the side. Second, that the system with which wave optics came into direct conflict had evolved after Young's work and independently of it, upon the discovery of polarization phenomena by Etienne Louis Malus in France. And that system, as in fact optics since the time of Newton (and even before), did not depend at its basic level upon light being a stream of particles, though many did indeed think light to be something like that. Instead, the fundamental conceptual and mathematical differences between wave and nonwave optics, at the deepest level, concerned whether light consisted of individually countable, discrete entities (rays) or a surface evolving through space in time under the aegis of phase. What actually occurred was that the ray-based system evolved rapidly after Malus's discovery as new polarization phenomena were found, while at nearly the same time Augustin Fresnel developed the mathematical and experimental foundations of wave optics in ways that, for a manifold of reasons, Young had not and likely could not have done.

Here, then, we have something that is unKuhn-like in one sense-namely, in not showing clear signs of anomaly and crisis among the originators of a novel scheme- but very Kuhn-like in another, for these events clearly do indicate that each system had evolved (and quite rapidly) a striking internal coherence grounded on unstated but firmly held ways of treating problems, ways that showed themselves only through the examination of the exemplary problems that each sought to solve. Reading only prefatory words about the systems, words intended to persuade, almost never reveals the ways in which a system actually works; that can be found only by trying to understand, step by step, how practitioners went about solving problems. This is why Kuhn placed so much emphasis in Structure on back-of-the-chapter problems in physical science and mathematics texts, texts of a sort that first began to appear in the eighteenth century. Trained as a physicist himself, Kuhn was convinced that the only way to learn how to be successful (i.e., to be considered a proper member of the community) was to set up, articulate, and solve problems in ways that the community accepted. Training and apprenticeship are consequently often, though hardly always (as, e.g., when a set of practitioners scarcely exists at all), critically important for someone fruitfully to enter an established field.

Which is why my third book, The Creation of Scientific Effects, explored how Heinrich Hertz, apprenticed under Hermann von Helmholtz in late I87os 
Berlin, came to create novel electrodynamic phenomena, including propagating electromagnetic waves. ${ }^{3}$ Hertz learned from Helmholtz a particular way of attacking problems in electrodynamics, a way that was only marginally consistent with contemporary British field theory, differing from the latter at fundamental levels, including the most basic concept of electric charge. Hertz attacked problems assigned to him by Helmholtz, and so thoroughly had he absorbed the latter's way of thinking about physics interactions that he succeeded in solving a problem that Helmholtz-the very creator of the system - had initially stumbled over. And then, years later, when Hertz did succeed in generating and detecting electric waves in air, he initially thought that the type of waves he had produced conformed to Helmholtz's way of thinking and not to Maxwell's. When he eventually decided otherwise, and developed the fundamental mathematico-physical scheme for what became antenna theory years later, Hertz did not adopt British field theory, for he continued to think about electric charge in ways that the latter found inimical. Here, then, we have something that does look like an evolving Kuhnian crisis at the heart of what I termed Helmholtzian physics, one that emerged rapidly as a result of a discovery that at first seemed to be consistent with it but that even more rapidly proved anomalous. And the resolution of the crisis within several years did lead to the production of an electrodynamics based on what became a canonical set of four "Maxwell equations" soon coupled to the "Lorentz force" on electric particles.

These events and the ones discussed in my Wave Theory also show, quite strikingly, the existence of something very like what Kuhn termed "incommensurability," which has proven to be a vexed and contentious term, particularly for philosophers of a strongly realist bent, and one that remained unformed in Structure itself. Nevertheless, the core of the notion is certainly there, and those of us taught by Kuhn picked up by example what he had in mind. Over the years he worked it through, until in his last decade he had pinned the concept down to the ways in which scientific terms constitute a tree of kinds in such a fashion that any given term has at most one immediate antecedent, as in a taxonomic system. ${ }^{4}$ That sounds rather abstract, and it is

3. Jed Z. Buchwald, The Creation of Scientific Effects: Heinrich Hertz and Electric Waves (Chicago: University of Chicago Press, 1994).

4. I learned about Kuhn's revised understanding of incommensurability in conversation with him. He never finished a manuscript on the subject. Elements of it can be gleaned from his 1990 presidential address to the Philosophy of Science Association, "The Road since Structure," in The Road since Structure (Chicago: University of Chicago Press, 2000), 90-I20. 
(partly because Kuhn never developed it into something tied to the roles of instrumentation), but it is nicely descriptive of what seems to be the case historically.

In Wave Theory and a subsequent article written after discussion with Kuhn, I argued that a tree of kinds drawn to exemplify how each system treated polarization exhibited the signs of incommensurability, in that a kind term in the one scheme overlapped with more than one such term in the other. ${ }^{5}$ Similarly, in both of my two first books, kind terms involving electric charge and fields or forces crossed disbarred boundaries when trying to apply a term from one scheme to another. And in all three cases one could find examples in which a practitioner of one scheme, trying to argue against an alternative, or just to use an alternative's successful results, inevitably worked the alternative scheme in a way that violated the relationships among its entities. That is assuredly a solid indication of Kuhnian incommensurability, albeit locked down to specifics and avoiding a mushy, global sense of the term that has so often confused or even angered readers of Structure - though I do maintain that a careful reader can find these elements there as well.

Despite the fact that Kuhn came rapidly to be seen as someone who did not think that scientific work could in any reasonable sense be thought true, he had no such notion in mind, and he never taught as much to his students, at least that I can recall. He did not think, and it remains an arguable point, that there is much meaning to asserting that science evolves ever more closely to Truth, for he did not consider such a thing to be accessible. But does a scientific field bud and divide to generate new fields, each of which constitutes problems whose solutions, it can meaningfully be said, are true? With that Kuhn would agree. He would agree as well that progress does occur, in the sense of the generation of an ever-greater set of successfully solved problems within the normal practice of a field, and of the effective subsumption of some of these problems in succeeding fields. This does not always occur, he would argue, because some problems are simply dropped as meaningless. For example, in my own work, one might in early nineteenth-century France ask: How many rays of a given color in a polarized set are deflected by means of a birefringent

5. Jed Z. Buchwald, "Kinds and the Wave Theory of Light," Studies in the History and Philosophy of Science 23 (1992): 39-74. For related matters see Jed Z. Buchwald and George E. Smith, "Incommensurability and the Discontinuity of Evidence," Perspectives on Science 9 (2002): 463-98; Jed Z. Buchwald and George E. Smith, “Thomas S. Kuhn, 1922-1996,” Philosophy of Science 64 (1998): 36I-76; Jed Z. Buchwald, "Design for Experimenting," in World Changes: Thomas Kuhn and the Nature of Science, ed. Paul Horwich (Cambridge, MA: MIT Press, I992), I69-206. 
crystal into a given angle? Fresnel's wave scheme makes the question meaningless, replacing it with the intensity at a given polarization angle of a particular optical frequency. Since rays are not preserved in wave optics, the alternative formulation easily generates a galaxy of meaningless consequences.

My most recently published (co-authored) book traverses rather different terrain, since here the issues range from archaeological expropriation during the Bourbon Restoration to censorship, religious revanchism, imagined pasts, and the question of who could control antiquity: calculating scientists or philological historians. ${ }^{6}$ Still, here too we find Kuhnian traces, since the communities in question usually talked past one another, and discord reigned even among the computing scientists as each group tried to forge its own version of antiquity by means of computations rejected by, and often not understood by, others. Kuhn remains relevant today precisely because he insisted on probing beneath the surface of scientific discourse to reveal the unstated but powerfully operative practices and beliefs that characterize a group. That kind of probing analysis requires immersion in the details of often arcane computations and arguments. Few did it in the past and few, Kuhn felt, do it today. More's the pity.

6. Jed Z. Buchwald and Diane Greco Josefowicz, The Zodiac of Paris: How an Improbable Controversy over an Ancient Artifact Provoked a Modern Debate over Religion and Science (Princeton, NJ: Princeton University Press, 20Io). 